\title{
Peningkatan Kemampuan Pemahaman TOEFL Mahasiswa Teknik Sipil Universitas Muhammadiyah Sukabumi
}

\author{
${ }^{(1)}$ Ramdan Sukmawan, ${ }^{(2)}$ Lusi Susilawati, ${ }^{(3)}$ Siska Hestiana \\ ${ }^{1,2,3)}$ Program Studi Sastra Inggris, Fakultas Ilmu Administrasi dan Humaniora, \\ Universitas Muhammadiyah Sukabumi, Indonesia \\ Email: ${ }^{1}$ ramdansukmawan@ummi.ac.id, ${ }^{2}$ lusi@ummi.ac.id ${ }^{3}$ siskahestiana82@gmail.com
}

\begin{tabular}{ll} 
INFORMASI ARTIKEL & ABS TRA K \\
\hline Kata Kunci: & Penguasaan TOEFL sangatlah penting bagi mahasiswa tanpa terkecuali untuk \\
Kemampuan_1 & mahasiswa Teknik Sipil sekali pun. Namun, melihat kemampuan pemahaman \\
Mahasiswa_2 & TOEFL mahasiswa yang masih kurang dan jauh dari kata memuaskan dengan \\
TOEFL_3 & skor TOEFL yang diraih relatif kecil. Maka dari itu diperlukan sebuah solusi \\
Pelatihan_4 & untuk meningkatkan kemapuan TOEFL mahasiswa. Untuk itu dilakukanlah \\
Peningkatan_5 & pelatihan TOEFL yang bertujuan untuk meningkatkan kemampuan pemahaman \\
& mahasiswa terhadap soal-soal tes TOEFL. Peningkatan kemampuan pemahaman \\
& tes TOEFL ini meliputi pemahaman menyimak percakapan bahasa Inggris, \\
& struktur gramatika bahasa Inggris, dan pemahaman teks bahasa Inggris. Tidak \\
& hanya itu saja, mahasiswa juga diberikan strategi-strategi yang harus dilakukan \\
& dalam mengikuti tes dan tips-tips yang memudahkan untuk mengerjakan soal-soal \\
& tes TOEFL. Dengan melihat hasil perbandingan skor tes awal dan tes akhir ada \\
& peningkatan skor TOEFL yang diperoleh mahasiswa. Ini artinya pelatihan TOEFL \\
& mahasiswa bisa dikatakan berhasil. Ada peningkatan kemampuan pemahaman \\
& mahasiswa terhadap soal-soal TOEFL setelah dilakukan pelatihan. Ini dibuktikan \\
& dengan adanya perubahan skor atau peningkatan skor dalam skor listening, \\
& writing, dan reading sehingga skor akhir TOEFLnya meningkat daripada skor \\
& sebelumnya.
\end{tabular}

ABSTRACT

${ }^{1)}$ Ramdan Sukmawan, ${ }^{(2)}$ Lusi Susilawati, ${ }^{3}$ Siska Hestiana Peningkatan Kemampuan Pemahaman TOEFL Mahasiswa Teknik Sipil Universitas Muhammadiyah 
Vol.2 No.2, Maret 2022, pp 41-52

Keywords:

Competency_1

Student_2

TOEFL_3

Training_4

Increasing 5
It is essential for students of university to master TOEFL, including the students of Civil Engeenering academic program. However, their competency of TOEFL comprehension was still lack and far from satisfactory of which their TOEFL scores were relatively low. Therefore, a solution was required to improve their TOEFL scores. For this reason, TOEFL training aims at improving students' comprehension on TOEFL test questions. Such comprehension includes listening comprehension, structure and written expression, dan reading comprehension. In addition, they were also given several strategies in taking the test, as well as the tips to make it easier in working on the TOEFL test questions. The result of the training showed that there was the improvement of their scrores which could be seen from their pre-test and post-test scores. Therefrore, it indicates that the traning was successful. There was an increase in students' understanding of TOEFL questions after training. This was proven by the change in score or increase in scores of listening, writing, and reading so that the final scores of the TOEFL were increasing from the previous ones.

This is an open access article under the CC-BY-SA license.

\section{PENDAHULUAN}

Penguasaan mahasiswa terhadap TOEFL sangatlah penting karena TOEFL dapat digunakan untuk berbagai kepentingan khususnya yang berhubungan dengan akademik mahasiswa. TOEFL singkatan dari Test of English as a Foreign Language, yaitu sebuah tes yang dirancang untuk mengukur kemampuan bahasa Inggris seseorang yang bahasa pertama atau bahasa ibunya bukan bahasa Inggris (Rogers, 2011), begitu pun dengan mahasiswa Program Studi Teknik Sipil Universitas Muhammadiyah Sukabumi, mereka diharuskan memiliki skor TOEFL yang memenuhi standar yang telah ditentukan oleh Program Studi. Para mahasiswa Teknik Sipil akan mengikuti tes TOEFL yang biasanya diadakan oleh Laboratorium Bahasa dan skornya harus mencapai setidaknya 400. Tes TOEFL yang dilakukan oleh mahasiswa adalah tes TOEFL PBT (Paper Based Test) meliputi tes listening comprehension, structure and written expression, dan reading comprehension. Test TOEFL PBT ini cocok dilakukan bagi mereka yang jaringan internetnya sangat terbatas (Mustafa \& Anwar, 2018).

TOEFL jenis PBT ini dilakukan dengan menjawab soal-soal pada kertas jawaban dengan menggunakan pensil 2B. Skor minimal yang dicapai dalam PBT ini minimal 310, sedangkan skor maksimalnya adalah 667 (Irawati \& Widiyantari, 2016). Tes TOEFL ini memiliki tingkat kesukaran tersendiri bagi mahasiswa Teknik Sipil karena materi-materi yang ada dalam tes tersebut sangatlah berbeda dengan apa yang telah dipelajari dalam English for Specific Purpose for Civil Enginering (ESP). Meskipun mahasiswa Teknik Sipil di semester pertama dan kedua mendapatkan mata kuliah ESP yang meliputi pembelajaran bahasa Inggris seperti aspek listening, speaking, reading, dan writing. Namun mereka membutuhkan strategi karena strategi dapat meningkatkan skor TOEFL (Nurhayati \& Nehe, 2016). Selain itu dibutuhkan juga tips dan pembiasaan terhadap materi-materi tes TOEFL. Maka dari itu, diperlukan kiranya pelatihan TOEFL untuk mahasiswa Teknik Sipil agar mereka memperoleh kemampuan dalam pemahaman terhadap soal-soal tes TOEFL. Dengan adanya pemahaman diharapkan skor TOEFLnya dapat meningkat dan dapat mencapai skor maksimal 400. Untuk dapat meningkatkan skor TOEFL dibutuhkan pemahaman pada tiap bagian soal tes TOEFL oleh mahasiswa yang tentunya merupakan suatu keharusan yang harus dikuasai untuk mendapatkan

1)Ramdan Sukmawan, (2) Lusi Susilawati, ${ }^{3}$ Siska Hestiana

Peningkatan Kemampuan Pemahaman TOEFL Mahasiswa Teknik Sipil Universitas Muhammadiyah Sukabumi 
skor yang tinggi. Pemahaman tersebut meliputi pemahaman menyimak percakapan bahasa Inggris, struktur gramatika bahasa Inggris, dan pemahaman teks bahasa Inggris. Berdasarkan permasalahan di atas, maka pelatihan TOEFL perlu dilakukan dengan tujuan untuk meningkatkan kualitas kemampuan mahasiswa Program Studi Teknk Sipil dalam memahami percakapan bahasa Inggris, struktur gramatika bahasa Inggris, dan teks bahasa Inggris sehingga skor TOEFL mereka menjadi meningkat.

\section{MASALAH}

Dari permasalahan yang ada yang telah diuraikan, dapat dirumuskan masalah sebagai berikut:

1. Bagaimana pelatihan pemahaman TOEFL mahasiswa dapat meningkatkan kemampuan mahasiswa mengerjakan soal-soal TOEFL sehingga skor yang mahasiswa peroleh meningkat?

2. Apa strategi-strategi yang digunakan mahasiswa untuk dapat menjawab soal-soal tes TOEFL sehingga

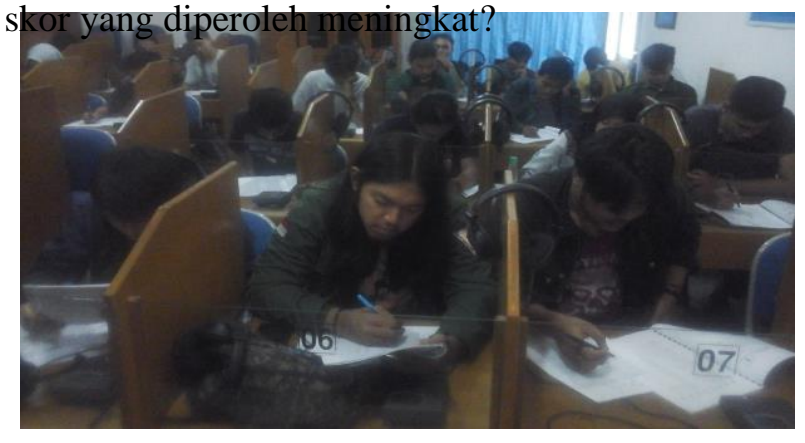

Gambar 1. Pelatihan TOEFL Mahasiswa

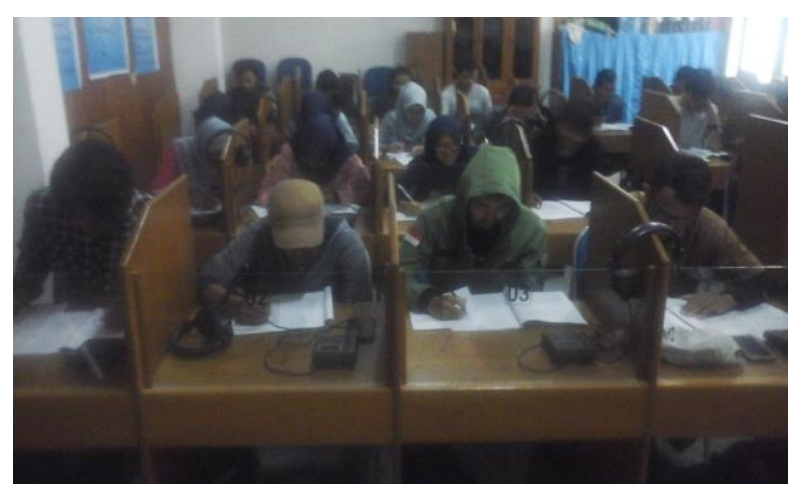

Gambar 2. Pelatihan TOEFL Mahasiswa

${ }^{1)}$ Ramdan Sukmawan, ${ }^{(2)}$ Lusi Susilawati, ${ }^{3}$ Siska Hestiana Peningkatan Kemampuan Pemahaman TOEFL Mahasiswa Teknik Sipil Universitas Muhammadiyah Sukabumi 


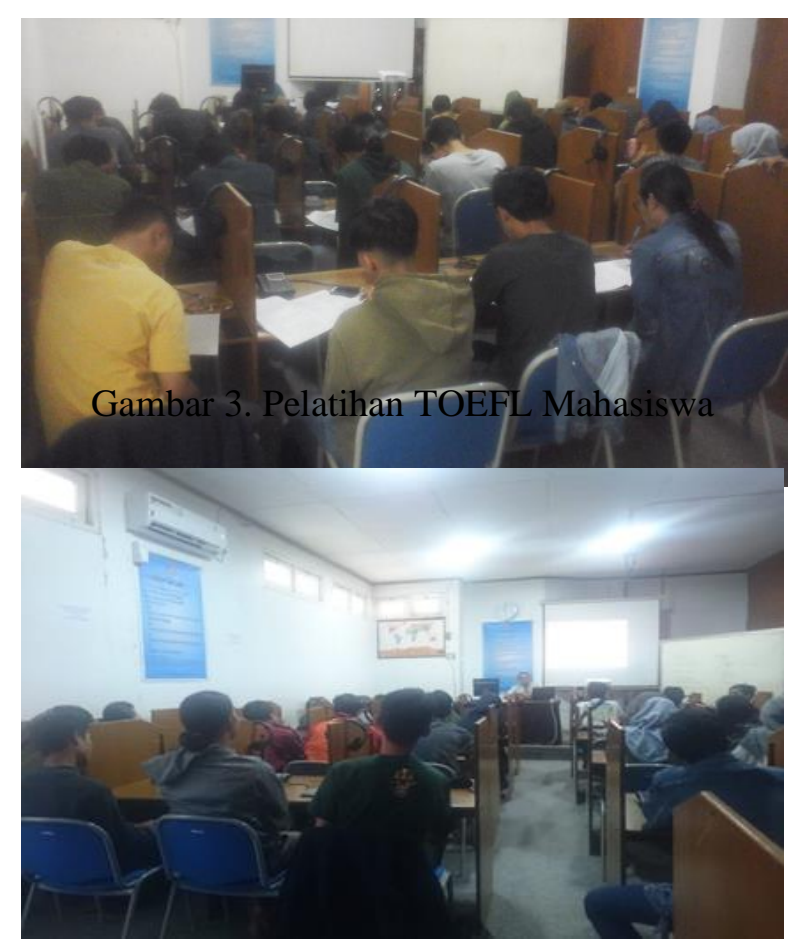

\section{METODE}

Gambar 4. Pelatihan TOEFL Mahasiswa

Pelaksanaan kegiatan peningkatan kompetensi pemahaman TOEFL mahasiswa dilakukan dalam beberapa tahap, yaitu: (1) sosialisasi, (2) pembuatan modul (3) pelatihan, dan (4) evaluasi.

Sosialisasi dilakukan dengan memberikan penjelasan kepada mahasiswa bagaimana cara untuk dapat memahami soal-soal tes TOEFL, materi-materi apa saja yang biasanya ada dan muncul dalam tes, dan strategi apa yang harus dilakukan oleh mahasiswa agar dapat mengerjakan soal-soal dengan mudah tanpa merasa kesulitan dan tertekan.

Modul pelatihan TOEFL dibuatkan terlebih dahulu sebelum pelaksanaan pelatihan dan dibagikan kepada mahasiswa. Tujuan pembuatan modul ini dilakukan agar memudahkan mahasiswa dalam mengikuti pelatihan karena modul sudah dilengkapi dengan soal-soal latihan, strategi, dan tips-tips dalam pemahaman menyimak percakapan bahasa Inggris, struktur gramatika bahasa Inggris, dan pemahaman teks bahasa Inggris. Modul tersebut terdiri dari dua belas bab dengan materi sebagai berikut; Bab 1) Strategies for Listening Comprehension, Bab 2) Listening Comprehension Subjects, Bab 3) Strategies for Guessing the Answer, Bab 4) Practice for Listening Comprehension, Bab 5) Strategies for Structure and Written Expression, Bab 6) Structure and Written Expression Subjects, Bab 7) Strategies for Guessing the Answer, Bab 8) Practice for Structure and Written Expression, Bab 9) Strategies for Reading Comprehension, Bab 10) Reading Comprehension Subjects, Bab 11) Strategies for Guessing the Answer, dan Bab 12) Practice for Reading Comprehension.

Pelatihan ini dilaksanakan setiap hari sabtu pukul 10.30 sampai dengan selesai yang bertempat di Laboratorium Bahasa Gedung A/26 Universitas Muhammadiyah Sukabumi. Pelatihan peningkatan pemahaman TOEFL mahasiswa ini meliputi pemahaman menyimak percakapan bahasa Inggris, struktur gramatika bahasa Inggris, dan pemahaman teks bahasa Inggris. Pelatihan pemahaman menyimak diarahkan untuk memahami makna percakapan

${ }^{1)}$ Ramdan Sukmawan, ${ }^{(2)}$ Lusi Susilawati, ${ }^{3}$ Siska Hestiana Peningkatan Kemampuan Pemahaman TOEFL Mahasiswa Teknik Sipil Universitas Muhammadiyah Sukabumi 
berbahasa Inggris baik percakapan singkat dan percakapan yang berupa monolog bahasa Inggris dalam konteks kehidupan sehari-hari penutur bahasa Inggris. Untuk pelatihan struktur gramatika bahasa Inggris diarahkan untuk penguasaan struktur tata bahasa Inggris. Selanjutnya, pelatihan pemahaman teks diarahkan kepada kemampuan dalam memahami teksteks bahasa Inggris. Tidak hanya itu saja, mahasiswa juga diberikan strategi-strategi yang harus dilakukan dalam mengikuti tes dan tips-tips yang memudahkan untuk mengerjakan soalsoal tes TOEFL.

Secara umum pelatihan TOEFL mahasiswa ini terdiri dari empat kegiatan, yaitu yang pertama adalah orientasi, yang kedua yaitu pelatihan, yang ketiga yakni penguatan dan yang terakhir merupakan penilaian. Pada tahap orientasi, mahasiswa diharuskan fokus dan siap dalam mempelajari materi-materi tes TOEFL. Tahap orientasi ini menggunakan teknik penjelasan. Penjelasan yang diberikan kepada mahasiswa dapat dipadukan dengan tanya jawab. Tahap berikutnya yaitu tahap pelatihan dilakukan dengan berdiskusi dan memberikan pemahaman kepada mahasiswa mengenai materi-materi, strategi-strategi, dan tips-tips dalam menyimak percakapan bahasa Inggris, struktur gramatika bahasa Inggris, dan pemahaman teks bahasa Inggris. Pada tahap penguatan mahasiswa, instruktur memberi latihan soal-soal tes pemahaman menyimak percakapan bahasa Inggris, struktur gramatika bahasa Inggris, dan pemahaman teks bahasa Inggris. Untuk penilaian dilakukan dengan mengukur pencapaian skor tes TOEFL mahasiswa melalui proses evaluasi, yaitu suatu proses kegiatan yang menilai tingkat keberhasilan dengan cara pencarian informasi melalui sistem pembelajaran (Febriana, 2021). Tahapan evaluasi ini dilaksanakan dengan melakukan tes awal TOEFL dan tes akhir TOEFL mahasiswa untuk mengetahui kemajuan pemahaman mahasiswa atas materi-materi tes TOEFL yang sudah diberikan dan dilatihkan.

\section{HASIL DAN PEMBAHASAN}

Pelatihan TOEFL ini adalah Pelatihan TOEFL Mahasiswa yang bertujuan untuk meningkatkan kualitas kemampuan mahasiswa dalam pemahaman menyimak percakapan bahasa Inggris, struktur gramatika bahasa Inggris, dan pemahaman teks bahasa Inggris. Pelatihan ini diikuti oleh 23 mahasiswa Program Studi Teknik Sipil. Adapun untuk pelaksanaan pelatihan TOEFL bagi mahasiswa, untuk materi-materi dan strategi-strategi serta tips-tips mengerjakan soal tes akan diuraikan sebagai berikut.

Pelatihan TOEFL diarahkan ke pencapaian pemahaman materi-materi pemahaman menyimak percakapan bahasa Inggris yaitu di antaranya:

1. Pemahaman idiom dan ungkapan percakapan bahasa Inggris.

2. Pemahaman makna yang dinyatakan secara tidak langsung dalam percakapan.

3. Pemahaman menjawab pertanyaan tertentu pada sebuah percakapan pendek.

4. Pemahaman interpretasi pada nada bicara penutur dan petutur pada sebuah percakapan.

5. Pemahaman inferensi atas sebuah percakapan.

6. Strategi dalam pemahaman menyimak percakapan bahasa Inggris dan tips-tipsnya.

Selanjutnya, pelatihan struktur gramatika bahasa Inggris diarahkan ke pencapaian kompetensi pemahaman materi-materi yaitu di antaranya:

1. Bentuk dan fungsi nomina, verba, adjektiva, dan adverbia.

2. Struktur kalimat, anak kalimat, klausa adjektiva, klausa adverbia, dan klausa nomina.

3. Subjek dan kesesuaian verbanya dalam kalimat.

4. Kalimat aktif dan pasif, verbal noun, dan infinitif.

5. Preposisi, verba dalam kala bahasa Inggris, dan klausa pelengkap.

6. Strategi dalam pemahaman struktur gramatika bahasa Inggris dan tips-tipsnya.

${ }^{1)}$ Ramdan Sukmawan, ${ }^{(2)}$ Lusi Susilawati, ${ }^{3)}$ Siska Hestiana Peningkatan Kemampuan Pemahaman TOEFL Mahasiswa Teknik Sipil Universitas Muhammadiyah 
Selain itu, pelatihan pemahaman teks bahasa Inggris diarahkan ke pencapaian kompetensi pemahaman materi-materi yaitu di antaranya:

1. Kefaktualan pada teks, inferensi, dan struktur sintaksis kalimat dan rujukannya.

2. Jenis-jenis kosakata yang sering tidak berhubungan dengan konteks kalimat.

3. Pengaturan teks yang tersaji.

4. Ide utama, tujuan teks, dan judul yang sesuai untuk teks.

5. Menyatakan kembali (mengungkapkan sesuatu dalam kata yang berbeda atau dengan cara yang berbeda).

6. Sudut pandang penulis teks dan tekstual analogi yang biasanya ditemukan dalam teks.

7. Strategi dalam pemahaman teks bahasa Inggris dan tips-tipsnya.

Dalam praktiknya, pelatihan dilakukan dengan memberikan tes awal terlebih dahulu untuk mengetahui sejauh mana kemampuan mahasiswa dalam memahami soal-soal tes TOEFL dan berapa skor TOEFL yang dapat dicapai oleh mahasiswa. Ternyata skor awal tes TOEFL mahasiswa, tidak ada satu pun yang mencapai 400. Sebagian besar mahasiswa mendapatkan skor tes TOEFL di atas 300 dan di bawah 400.

Untuk itu, maka diadakan pelatihan TOEFL selama 12 kali pertemuan. Pelatihan ini wajib diikuti tanpa terkecuali karena kegiatan yang sama yang pernah dilakukan Utami \& Pirmansyah, (2018) menyatakan bahwa jika pelatihan tidak diikuti dengan lengkap maka akan terjadi penurunan skor. Dalam pelatihan ini, selain diberikan materi yang berkenaan dengan soal-soal tes TOEFL serta beberapa strategi dalam menjawab soal-soal TOEFL. Rosaria, Gunantar, \& Ellyawati (2021) menawarkan beberapa strategi dalam "menyimak", diantaranya adalah antisipasi topik dan pertanyaan yang dilakukan sebelum tes menyimak dilakukan, serta menentukan topik dan kesimpulan pada saat tes menyimak dilakukan, dan terakhir adalah mendengarkan percakapan secara runtut.

Pada bagian menyimak yang terdiri dari 50 soal terbagi ke dalam 3 bagian soal. Bagian A terdiri dari 30 soal di mana untuk strateginya mahasiswa diharuskan fokus kepada pembicara kedua. Si pembicara kedua yang sebenarnya mengungkapkan makna yang secara tidak langsung dinyatakan yang sekaligus merupakan jawaban terhadap apa yang sebenarnya dibicarakan dalam percakapan pendek antara pembicara pertama dan kedua.

Di bagian B, percakapan yang dilakukan oleh pembicara pertama dan kedua lebih panjang dibandingkan percakapan di bagian A. Pada bagian B, pembicara pertama dan kedua mungkin akan mendapat giliran berbicara tiga kali secara bergantian. Satu percakapan untuk 4 atau 5 pertanyaan. Hal ini berbeda seperti pada bagian A, satu percakapan untuk satu pertanyaan. Yang harus mahasiswa cermati adalah kata-kata kunci tertentu yang muncul dalam percakapan antara pembicara pertama dan kedua yang merupakan jawaban dari setiap pertanyaan yang diajukan pada bagian pemahaman menyimak.

Selanjutnya, di bagian $\mathrm{C}$ pemahaman menyimak tidak seperti pada bagian A dan B yang mana mahasiswa diperdengarkan pada percakapan singkat dan panjang antara dua orang pembicara. Pada bagian pemahaman menyimak di bagian $\mathrm{C}$, mahasiswa diberikan sebuah monolog atau (short lecture) yang diperdengarkan. Satu monolog ini biasanya untuk 4 pertanyaan yang nanti akan ditanyakan. Waktu yang dibutuhkan untuk menjawab tiap soal antara $12-15$ detik.

Adapun strategi yang harus dilakukan dalam tes pemahaman menyimak percakapan bahasa Inggris adalah sebagai berikut.

1. Lihatlah dengan cepat pilihan-pilihan jawaban pada soal sebelum tes menyimak diperdengar kan.

2. Ketika percakapan diperdengarkan, berkonsentrasilah pada makna percakapan yang diujarkan oleh pembicara kedua.

3. Ingatlah dalam tes hanya diberikan beberapa detik untuk menjawab pertanyaan. Maka dari itu, jangan terlalu lama menentukan pilihan jawaban yang benar.

4. Biasanya tidak ada hubungannya antara pertanyaan dan percakapan yang diperdengarkan,

1)Ramdan Sukmawan, (2) Lusi Susilawati, ${ }^{\text {3) }}$ Siska Hestiana Peningkatan Kemampuan Pemahaman TOEFL Mahasiswa Teknik Sipil Universitas Muhammadiyah 
untuk itu haruslah melakukan interpretasi makna yang tidak dinyatakan secara tidak langsung.

5. Pada bagian A pemahaman menyimak, tidak perlu percakapan yang diperdengarkan untuk dapat dipamahami semua, hal yang harus dilakukan adalah berkonsentrasi pada beberapa kata kunci yang ada dalam percakapan yang biasanya berupa verba atau nomina yang diujarkan oleh pembicara kedua.

6. Di bagian A, berikanlah perhatian khusus pada penekanan kata dan pada intonasi baik yang meninggi atau pun menurun dari pernyataan yang diujarkan oleh pembicara kedua. Seringkali, intonasi pembicara tersebut mengindikasikan makna sebaliknya dari apa yang dikatakan atau makna yang berbeda dari yang sebenarnya diujarkan.

7. Pada bagian B, pertanyaan-pertanyaan selalu berdasarkan susunan informasi yang disajikan pada percakapan antara pembicara pertama dan kedua. Untuk menjawab pertanyaan-pertanyaan yang diberikan, harus memahami semua makna yang dibicarakan oleh kedua pembicara dalam percakapan tersebut.

Selanjutnya adalah tes struktur gramatika bahasa Inggris, yaitu sebuah tes yang mengukur kemampuan seseorang dalam mengidentifikasi kesalahan-kesalahan gramatika (Matthiesen, 2017). Tes struktur gramatika bahasa Inggris ini terdiri dari 40 soal dimana terbagi menjadi 2 bagian, yaitu bagian A (structure) terdiri dari 15 soal dan bagian B (written expression) terdiri dari 25 soal. Pada tes ini alokasi waktu yang disediakan adalah 25 menit, yang mana ada sekitar 35-37 detik untuk menjawab tiap pertanyaan pada bagian ini.

Di bagian A mahasiswa diharuskan untuk menemukan kata atau frase yang benar untuk melengkapi kalimat. Pada bagian B diharuskan mengidentifikasikan yang mana dari kata-kata atau frase-frase yang digarisbawahi yang tidak benar secara gramatikal dalam sebuah kalimat. Perbedaan antara bagian A dan B adalah bahwa di bagian A harus memilih pilihan jawaban yang benar sedangkan di bagian B harus memilih pilihan jawaban yang salah.

Topik-topik materi pada bagian struktur gramatika bahasa Inggris biasanya berupa materimateri akademik, hal-hal yang berkenaan dengan budaya, keilmuan, fakta-fakta sejarah, riwayat hidup tokoh ternama, dan lain sebagainya. Dalam tes bagian ini diharuskan mahasiswa berkonsentrasi pada nomina, verba, adjektiva, frase preposisi, frase adverbial, dan anak kalimat.

Tidak hanya dalam pemahaman menyimak percakapan bahasa Inggris, strategi pun harus dilakukan pada bagian pemahaman struktur gramatika bahasa Inggris yaitu sebagai berikut:

1. Terkadang dalam tes seringkali tidak dapat menentukan pilihan jawaban yang benar. Pilihanlah salah satu jawaban yang mana saja. Siapa tahu jawaban yang dipilih benar.

2. Jika tidak memahami kalimat yang ada pada tes ini, cobalah untuk mengidentifikasi subjek dan verba karena keduanya harus dalam bentuk kala kini untuk kalimat tersebut agar bertatabahasa.

3. Setelah dapat mengidentifikasikan subjek dalam sebuah kalimat, tentukanlah apa jenis verba yang harus mengikutinya dan apa yang tidak boleh mengikutinya, tergantung bentuk subjeknya apakah tunggal atau jamak.

4. Penggunaan artikel sangat penting karena artikel dapat membantu membedakan sebuah nomina dari sebuah verba. Sebagian besar nomina tunggal dalam bahasa Inggris harus ada artikelnya atau kata ganti kepunyaan. Jika menemukan kata ganti kepunyaan, atau preposisi, sudah dipastikan itu semua adalah nomina frasa. Ingatlah selalu, frase preposisi bukanlah bagian dari sebuah subjek kalimat.

5. Pada subjek ketiga tunggal dalam bentuk kala kini, apakah subjek orang ketiga tunggal seperti $h e$, she, it atau verbanya harus berakhiran $-s$ baik subjek dan verbanya tidak ada $-s$. Jika nomina mendeskripsikan nomina yang lain, bentuk jamak $-s$ dapat digunakan hanya pada akhir nomina.

6. Bila menemukan frase verba, perhatikanlah kata kerja bantunya, verba yang terdiri dari dua kata dan verba yang memerlukan objek langsung. Jika frase verba ini dalam bentuk kata

${ }^{1)}$ Ramdan Sukmawan, ${ }^{(2)}$ Lusi Susilawati, ${ }^{\text {3) Siska Hestiana }}$ Peningkatan Kemampuan Pemahaman TOEFL Mahasiswa Teknik Sipil Universitas Muhammadiyah 
kerja be maka verba utamanya harus dalam bentuk ing untuk aktif atau-ed/past participle untuk bentuk pasifnya.

7. Perhatikanlah bentuk kala (tense) verbanya pada sebuah kalimat. Perhatikan kala dan verbanya atau kata lainnya dan haruslah kalimat tersebut memiliki keterangan waktu yang sesuai.

Pada bagian pemahaman teks bahasa Inggris yang terdiri dari empat sampai enam teks yang memiliki sekitar 200-450 kata untuk setiap teksnya. Sebuah teks biasanya untuk tujuh atau bahkan dua belas pertanyaan. Kebanyakan mahasiswa memiliki masalah untuk mengerjakan tes pada bagian pemahaman teks pada tes TOEFL. Topik-topik yang menjadi pembahasan pada teks biasanya hal-hal yang berkenaan dengan lingkungan akademisi atau teks-teks dari buku yang membicarakan deskripsi mata kuliah di universitas. Sebagian besar teks-teks tersebut membahas hal-hal yang berkenaan dengan bidang biologi, kimia, geografi, fisika, sejarah, biografi, ekonomi, ilmu-ilmu sosial, dan lain-lain.

Kemampuan dalam pembendaharaan kata bahasa Inggris akan sangat penting untuk mendapatkan skor yang tinggi pada tes bagian pemahaman teks bahasa Inggris. Hal ini senada dengan pernyataan (Sungatullina, Zalyaeva, \& Gorelova, 2016) bahwa dalam soal pemahaman membaca, pengetahuan kosa kata memegang peranan yang sangat penting. Adapun strategistrategi yang harus dilakukan pada bagian pemahaman teks bahasa Inggris mengadaptasi teori dari (Leong \& Leong, 2016), yaitu sebagai berikut:

1. Membaca cepat

2. Mengupas kosakata

3. Struktur dan organisasi I

4. Stuktur dan organisasi II

5. Memparafrase

6. Meringkas

7. Menyimpulkan

Setelah mahasiswa mendapatkan pelatihan, mereka diuji kembali pemahamannya terhadap apa yang telah mereka dapatkan dengan tes akhir TOEFL untuk melihat sejauh mana pemahamannya akan materi-materi TOEFL yang telah diberikan. Alhamdullilah, skor akhir mahasiswa mendapat peningkatan yang pada awal tes skor rata-rata yang diperoleh mahasiswa 342 dengan skor $300 \mathrm{ke}$ atas dan di bawah 400. Namun pada tes akhir ini, skor rata-rata TOEFL mahasiswa adalah 367. Ada peningkatan skor rata-rata yaitu sebesar 25 dengan skor rata-rata 300 ke atas bahkan ada yang memperoleh skor di atas 400, yaitu dengan skor 416 .

Berikut ini adalah daftar skor tes awal dan tes akhir mahasiswa yang mengikuti pelatihan.

Tabel 1. Daftar Skor Tes Awal TOEFL Mahasiswa Program Studi Teknik Sipil

\begin{tabular}{clccccc}
\hline & & \multicolumn{3}{c}{ Skor } & Sub & Total \\
No & \multicolumn{1}{c}{ Nama Mahasiswa } & Listening & Writing & Reading & Total & Skor \\
\hline 1 & Ryan Febriansyah & 35 & 35 & 25 & 950 & 317 \\
2 & Dimas Utri Sasongko & 37 & 35 & 28 & 1000 & 333 \\
3 & M. Rizal Fadillah & 37 & 35 & 32 & 1040 & 347 \\
4 & Fauzan Azhima & 37 & 33 & 28 & 980 & 327 \\
5 & Anjas Susanto Wijaya & 39 & 31 & 30 & 1000 & 333 \\
6 & Yoga Prasetyo D & 45 & 37 & 35 & 1170 & 390 \\
7 & Agung Nur Rochmat & 35 & 31 & 28 & 940 & 313 \\
8 & Yoghi Cahyo Nugroho & 39 & 36 & 35 & 1100 & 367 \\
9 & Adrian Rohmat & 40 & 40 & 31 & 1110 & 370 \\
10 & M. Iqbal Herdiansyah P & 35 & 30 & 35 & 1000 & 333 \\
11 & Kenza Nuraziz & 39 & 35 & 26 & 1000 & 333 \\
12 & Muhammad Bagja Kurnia & 40 & 36 & 31 & 1070 & 357 \\
& & & & & & 48 \\
\hline
\end{tabular}

Peningkatan Kemampuan Pemahaman TOEFL Mahasiswa Teknik Sipil Universitas Muhammadiyah 


\begin{tabular}{|c|c|c|c|c|c|c|}
\hline 13 & Rifa Agustiani R & 40 & 29 & 28 & 970 & 332 \\
\hline 14 & Ima Nurmalasari & 35 & 36 & 33 & 1040 & 347 \\
\hline 15 & Bayu Safputra & 36 & 35 & 30 & 1010 & 337 \\
\hline 16 & Riska Rahmawati Djunaedi & 41 & 29 & 35 & 1050 & 350 \\
\hline 17 & Zulfa Aulia Az-zahra & 36 & 37 & 32 & 1050 & 350 \\
\hline 18 & Ilham Hidayatullah & 39 & 36 & 31 & 1060 & 353 \\
\hline 19 & Dikky Rizkiandany & 35 & 35 & 30 & 1000 & 333 \\
\hline 20 & Sumaryono & 37 & 28 & 26 & 910 & 303 \\
\hline 21 & Yosep Perdiansyah & 34 & 41 & 28 & 1060 & 353 \\
\hline 22 & Agung Pratama & 36 & 33 & 29 & 980 & 327 \\
\hline 23 & Dicky Hasanuddin & 39 & 35 & 31 & 1050 & 350 \\
\hline
\end{tabular}

Tabel. 2 Daftar Skor Tes Akhir TOEFL Mahasiswa Program Studi Teknik Sipil

\begin{tabular}{clccccc}
\hline & & \multicolumn{3}{c}{ Skor } & Sub & Total \\
No & \multicolumn{1}{c}{ Nama Mahasiswa } & Listening & Writing & Reading & Total & Skor \\
\hline 1 & Ryan Febriansyah & 39 & 42 & 35 & 1160 & 387 \\
2 & Dimas Utri Sasongko & 37 & 41 & 33 & 1110 & 370 \\
3 & M. Rizal Fadillah & 37 & 37 & 35 & 1090 & 363 \\
4 & Fauzan Azhima & 38 & 37 & 36 & 1110 & 370 \\
5 & Anjas Susanto Wijaya & 39 & 38 & 31 & 1080 & 360 \\
6 & Yoga Prasetyo D & 45 & 43 & 37 & 1250 & 416 \\
7 & Agung Nur Rochmat & 39 & 36 & 34 & 1090 & 363 \\
8 & Yoghi Cahyo Nugroho & 44 & 33 & 35 & 1120 & 373 \\
9 & Adrian Rohmat & 45 & 37 & 33 & 1150 & 383 \\
10 & M. Iqbal Herdiansyah P & 34 & 38 & 32 & 1040 & 347 \\
11 & Kenza Nuraziz & 45 & 36 & 33 & 1140 & 380 \\
12 & Muhammad Bagja Kurnia & 39 & 39 & 33 & 1110 & 370 \\
13 & Rifa Agustiani R & 35 & 37 & 32 & 1040 & 347 \\
14 & Ima Nurmalasari & 36 & 38 & 35 & 1090 & 363 \\
15 & Bayu Saputra & 35 & 35 & 34 & 1040 & 347 \\
16 & Riska Rahmawati Djunaedi & 40 & 36 & 30 & 1060 & 353 \\
17 & Zulfa Aulia Az-zahra & 41 & 31 & 35 & 1070 & 357 \\
18 & Ilham Hidayatullah & 38 & 42 & 36 & 1160 & 387 \\
19 & Dikky Rizkiandany & 36 & 35 & 37 & 1080 & 360 \\
20 & Sumaryono & 37 & 36 & 35 & 1080 & 360 \\
21 & Yosep Perdiansyah & 37 & 41 & 35 & 1130 & 377 \\
22 & Agung Pratama & 36 & 33 & 34 & 1030 & 343 \\
23 & Dicky Hasanuddin & 39 & 35 & 33 & 1070 & 357 \\
\hline
\end{tabular}

Tabel 3. Daftar Skor Perbandingan Tes Awal dan Tes Akhir TOEFL

\begin{tabular}{llccc}
\hline No & \multicolumn{1}{c}{ Nama Mahasiswa } & $\begin{array}{c}\text { Skor } \\
\text { Awal }\end{array}$ & $\begin{array}{c}\text { Skor } \\
\text { Akhir }\end{array}$ & $\begin{array}{c}\text { Peningkatan } \\
\text { Skor }\end{array}$ \\
\hline 1 & Ryan Febriansyah & 317 & 387 & 70 \\
2 & Dimas Utri Sasongko & 333 & 370 & 37 \\
3 & M. Rizal Fadillah & 347 & 363 & 16 \\
4 & Fauzan Azhima & 327 & 370 & 43 \\
5 & Anjas Susanto Wijaya & 333 & 360 & 27
\end{tabular}




\begin{tabular}{clccc}
\hline \hline 6 & Yoga Prasetyo D & 390 & 416 & 26 \\
7 & Agung Nur Rochmat & 313 & 363 & 50 \\
8 & Yoghi Cahyo Nugroho & 367 & 373 & 6 \\
9 & Adrian Rohmat & 370 & 383 & 13 \\
10 & M. Iqbal Herdiansyah P & 333 & 347 & 14 \\
11 & Kenza Nuraziz & 333 & 380 & 47 \\
12 & Muhammad Bagja Kurnia & 357 & 370 & 13 \\
13 & Rifa Agustiani R & 332 & 347 & 15 \\
14 & Ima Nurmalasari & 347 & 363 & 16 \\
15 & Bayu Safputra & 337 & 347 & 10 \\
16 & Riska Rahmawati Djunaedi & 350 & 353 & 3 \\
17 & Zulfa Aulia Az-zahra & 350 & 357 & 7 \\
18 & Ilham Hidayatullah & 353 & 387 & 34 \\
19 & Dikky Rizkiandany & 333 & 360 & 27 \\
20 & Sumaryono & 303 & 360 & 57 \\
21 & Yosep Perdiansyah & 353 & 377 & 24 \\
22 & Agung Pratama & 327 & 343 & 16 \\
23 & Dicky Hasanuddin & 350 & 357 & 7 \\
\hline & Rata-rata dalam & 342 & 367 & 25 \\
\hline
\end{tabular}

Melihat perbandingan skor awal tes dan skor akhir tes TOEFL di atas terjadi peningkatan. Di awal tes, rata-rata skor tes yang dapat dicapai oleh mahasiswa 342. Setelah dilakukan pelatihan TOEFL, dan di akhir pelatihan mahasiswa diberikan tes akhir TOEFL terlihat skor yang diperoleh mahasiswa ada peningkatan. Rata-rata skor yang diraih mahasiswa menjadi 367. Walaupun tidak signifikan peningkatannya tetapi ada kenaikan skor rata-rata sebesar 25 . Ini artinya pelatihan TOEFL mahasiswa bisa dikatakan berhasil. Ada peningkatan kemampuan pemahaman mahasiswa terhadap soal-soal TOEFL setelah dilakukan pelatihan. Di lihat dari pemahaman mahasiswa dalam aspek pemahaman menyimak percakapan bahasa Inggris, struktur gramatika bahasa Inggris, dan pemahaman teks bahasa Inggris pun meningkat. Ini dibuktikan dengan adanya perubahan skor atau peningkatan skor dalam skor listening, writing, dan reading pada tabel 1 dan tabel 2 di atas. Untuk lebih mudah melihat perbandingannya, berikut adalah bagan perbandingan tes awal dan akhir serta kenaikannya.

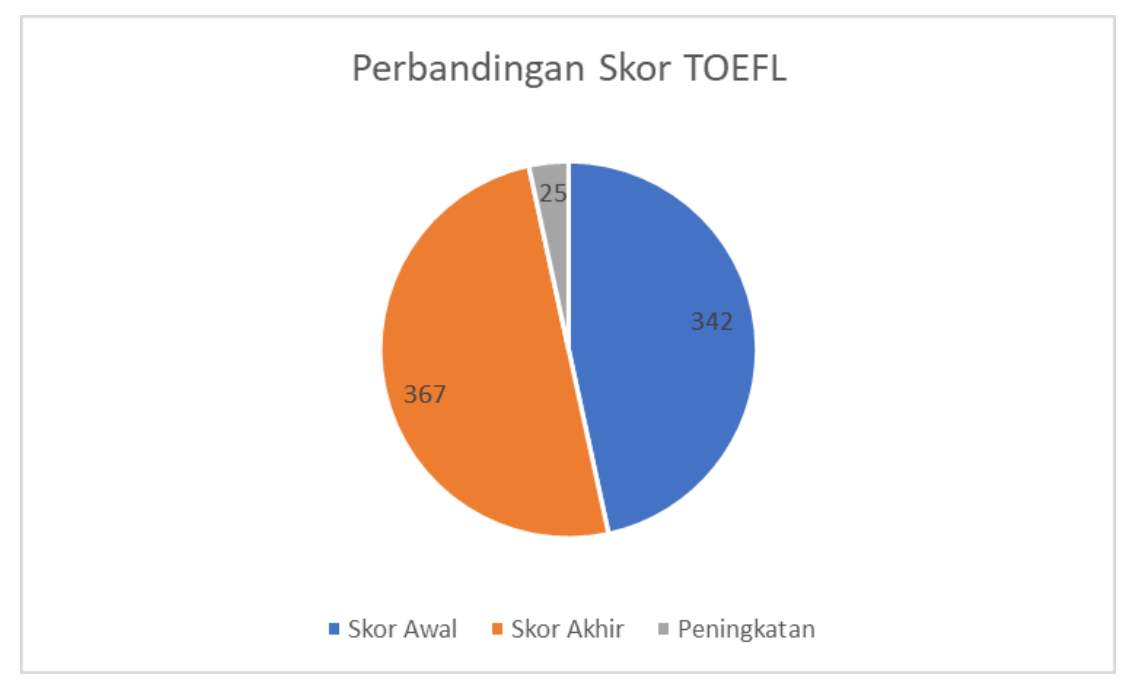

Gambar 5. Skor Perbandingan Tes Awal dan Tes Akhir 


\section{KESIMPULAN}

Kegiatan pelatihan TOEFL merupakan suatu cara yang sangat tepat dilakukan untuk meningkatkan skor TOEFL mahasiswa dengan cara meningkatkan kemampuan pemahaman mahasiswa melalui pelatihan TOEFL dengan penguasaan materi, strategi, dan tips serta pembiasaan dalam menjawab soal-soal tes TOEFL. Selain itu, dalam pelaksanaan pelatihan TOEFL ditempuh beberapa metode, yaitu sosialisasi, pembuatan modul, pelatihan, dan evaluasi. Hasil dari kegiatan pelatihan ini menunjukkan adanya peningkatan terhadap skor TOEFL mahasiswa, yaitu dari rata-rata skor awal 342 menjadi 367. Untuk lebih mengoptimalkan hasil skor TOEFL mahasiswa Program Studi Teknik Sipil, pelaksanaan pelatihan dapat dilakukan secara berkesinambungan. Artinya, pelatihan TOEFL mahasiswa tidak berhenti sampai di sini. Akan ada pelatihan-pelatihan TOEFL selanjutnya untuk mahasiswa dengan tujuan untuk meningkatkan kemampuan mahasiswa dalam hal penguasaan TOEFL. Selain itu, agar lebih efektif sebaiknya pelatihan TOEFL ini ditingkatkan dengan menggunakan test TOEFL IBT (Internet-Based Test), yaitu test TOEFL dengan menggunakan komputer yang terhubung dengan internet (Stirling, 2016).

\section{UCAPAN TERIMA KASIH}

Ucapan terima kasih disampaikan kepada Ketua Program Studi Teknik Sipil yang telah mempercayakan kepada kami untuk memberikan pelatihan peningkatan kemampuan pemahaman TOEFL mahasiswa Program Studi Teknik Sipil. Tidak lupa kami menghaturkan terima kasih yang sebesar-besarnya atas partisipasi dan peran aktif mahasiswa Teknik Sipil Universitas Muhammadiyah Sukabumi yang telah bersedia mengikuti pelatihan.

\section{DAFTAR PUSTAKA}

Febriana, R. (2021). Evaluasi Pembelajaran (PT Bumi Asmara, ed.). Jakarta.

Irawati, I., \& Widiyantari, Y. (2016). The Master of TOEFL. Yogyakarta: PT Bentang Pustaka. Retrieved from https://books.google.co.id/books?hl=id \&lr=\&id=b3snDQAAQBAJ\&oi=fnd \&pg=PP10\& $\mathrm{dq}=$ materi+toefl\&ots=acLW81C77H\&sig=gP6Io2h6EnXwyih2u16xZUk8b7o\&redir_esc $=\mathrm{y} \# \mathrm{v}=$ onepage $\& \mathrm{q}=$ materi toef $1 \& \mathrm{f}=$ false

Leong, K., \& Leong, E. (2016). Top theTOEFL : Unlocking the Secrets of Ivy League Students. Toh Tuck Link: World Scientific Publishing Co. Pte. Ltd.

Matthiesen, S. J. (2017). Barron's Essential Words for the TOEFL (Seventh Ed). Barron's Study Green. Retrieved from https://books.google.co.id/books?id=GVGIDgAAQBAJ

Mustafa, F., \& Anwar, S. (2018). Distinguishing TOEFL Score: What is the lowest Score Considered a TOEFL Score? Pertanika Journal of Social Sciences and Humanities, 26(3), 1995-2008.

Nurhayati, N., \& Nehe, B. M. (2016). An Analysis of Students' Strategies in Answering TOEFL. The Journal of English Language Studies, 01(01), 10-18.

Rogers, B. (2011). The Complete Guide to The TOEFL Test (Second Edi). Massachussetts: Heinle Cengage Learning.

Rosaria, S. D., Gunantar, D. A., \& Ellyawati, H. C. (2021). Strategi Mahasiswa Ilmu Komunikasi Universitas Semarang dalam Mengerjakan Soal Listening Comprehension TOEFL. Dinamika Sosial Budaya, 23(1), 74-83.

Stirling, B. (2016). 500 Words, Phrases, and Idioms for the TOEFL iBT plus Typing Strategies. Los Angeles: Nova Press.

Sungatullina, D. D., Zalyaeva, E. O., \& Gorelova, Y. N. (2016). Metacognitive Awareness of 
TOEFL Reading Comprehension Strategies. SHS Web of Conference. ERPA 2015. https://doi.org/10.1051/201

Utami, S. S., \& Pirmansyah, B. (2018). Peningkatan Skor Test Bahasa Inggris (TOEFL) Melalui Pelatihan Secara Intensif. Lingua Franca:Jurnal Bahasa, Sastra, Dan Pengajarannya, 2(2), 36. https://doi.org/10.30651/lf.v2i2.1477 